\title{
Working together to eliminate cervical cancer: a partnership across three countries "As mudanças no mundo são criadas por nós"
}

\author{
Mila Pontremoli Salcedo, Porto Alegre, Brazil, Houston, USA, Porto Alegre, Brazil; Cesaltina Lorenzoni, Maputo, \\ Mozambique, Maputo, Mozambique and Kathleen M Schmeler, Houston, USA
}

Mozambique is a country in sub-Saharan Africa with a population of 28 million and approximately $48 \%$ of the population living below the poverty line. ${ }^{1}$ It has one of the highest burdens of cervical cancer in the world, with an incidence rate of 42.8 and mortality rate of 35.7 per 100000 women. $^{2}$ These high rates are due to a combination of factors including lack of organized screening as well as few doctors and nurses trained to diagnose and treat cervical dysplasia and invasive cancer. Currently, in Mozambique, $<5 \%$ of eligible women are undergoing cervical screening. Furthermore, many of the women with abnormal screening results are being lost to follow-up and not undergoing the necessary procedures to diagnose and treat pre-cancerous lesions. ${ }^{3}$ The majority of women present with advanced cancer with limited options for treatment as there are no gynecologic oncologists or radiotherapy available.

In 2013, the MD Anderson Cancer Center began a collaboration with the Mozambique Ministry of Health $(\mathrm{MoH})$ to improve cervical cancer screening, diagnosis, and treatment. Given that Mozambique is a Portuguese-speaking country, MD Anderson invited partner institutions from Brazil to join the collaboration. Doctors, nurses, and researchers from Brazil and the USA have been working together to provide training

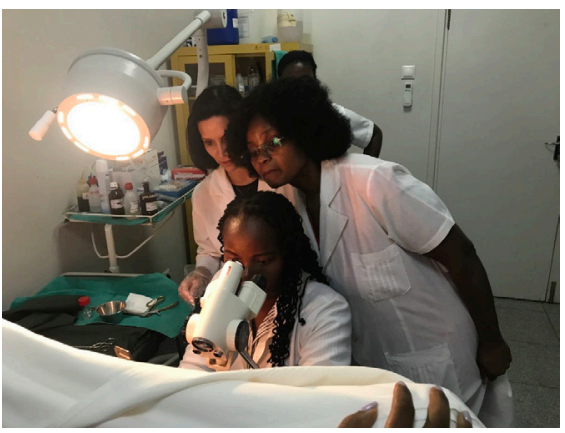

Figure 1 Colposcopy training

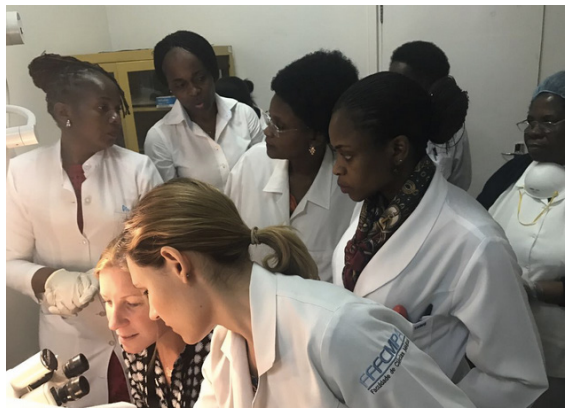

Figure 2 Colposcopy training

and mentoring to doctors and nurses in Mozambique in visual inspection with acetic acid (VIA), colposcopy, cervical biopsy, cryotherapy, and the loop electrosurgical excision procedure (LEEP)(figure 1)(figure 2). Together, we hold courses that include didactic lectures, hands-on training using simulation models, and supportive supervision for the providers to perform these procedures in patients (figure 3). The training is supported by monthly video conferences using the Project ECHO telementoring program. ${ }^{4}$

We are also evaluating improved methods of screening over VIA, the standard of care in Mozambique. In 2018 we launched the Capulana trial, the first collaborative research study between the MD Anderson Cancer Center, Brazilian partners, and the Mozambique $\mathrm{MoH}$ to evaluate the feasibility of primary human papillomavirus (HPV) testing for cervical

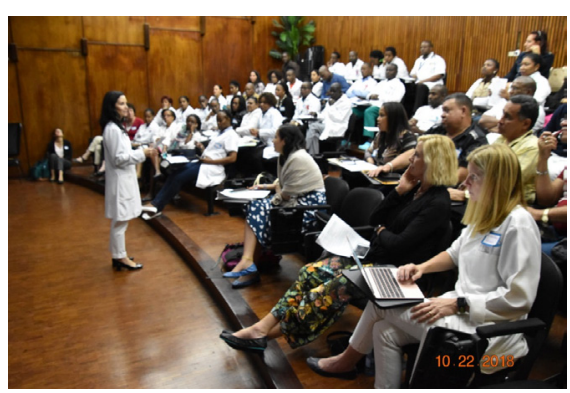

Figure 3 Didactic lecturesduring Colposcopy and LEEP course

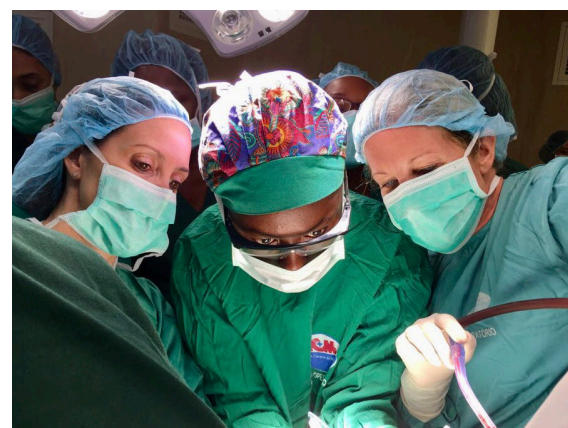

Figure 4 Surgical training

screening in Mozambique. Thus far, 430 of a planned 2000 women have been enrolled. Research and clinical experts from the MD Anderson Cancer Center and Brazil travel to Mozambique quarterly to provide ongoing training, mentorship, and capacity building. We recently received funding from the United States Agency for International Development (USAID) to expand HPV screening and treatment of pre-invasive disease to other regions of the country.

To impact the high cervical cancer rates in Mozambique, we are working as a multidisciplinary and global team. We are all teaching and learning together in order to better screen and treat the women in Mozambique.(figure 4) This work gives all of us an incredible sense of fulfilment and gratitude. By bringing providers from three countries together, we help each other to provide better care for patients in our own countries, but also the patients of the world. Together we can work to reduce the health disparities and the burden of cervical cancer worldwide.

"As mudanças no mundo são criadas por nós" is a Portuguese expression that means we are the ones that can create change in the world!

Correspondence to Dr Kathleen M Schmeler,Gynecologic Oncology, M.D. Anderson Cancer Center, Houston, USA; KSchmele@ mdanderson.org 


\section{Corners of the World}

Collaborators André Lopes; Elvira Luis; Geórgia Fontes Cintra; Magda Ribeiro; Marcelo de Andrade Vieira; Renato Moretti Marques; Arlete Artur Neta Mariano; Berta Xavier dos Santos; Cristina Oliveira; Dércia Changule; Eliane Carmo dos Santos Monteiro; Ellen Baker; Flora Mabota; José Humberto Tavares Guerreiro Fregnani; Joseph P. Thomas; Mark F. Munsell; Mário Chalyamba, Melissa Lopez Varon, Natacha Phoolcharoen, Ricardina Rangeiro; Rosália Francisco Macaringue, Saquina Mariamo Manhica, Siro Daúd; Viviane Andrade.

Contributors MPS, CF, and KMS are the three Program co-directors from Brazil, Mozambique, and the USA, respectively.

Funding These projects are supported in part by the Prevent Cancer Foundation, the Anadarko Petroleum Corporation, the Dunaway Family Fund, the Joe Family Fund, and the Giles-0'Malley Foundation.
Competing interests None declared.

doi:10.1136/ijgc-2019-000372

Patient consent for publication Not required.

Provenance and peer review Commissioned; internally peer reviewed.

(c) IGCS and ESGO 2019. No commercial re-use. See rights and permissions. Published by BMJ.

\section{Check for updates}

To cite Salcedo MP, Lorenzoni C, Schmeler KM. Int J Gynecol Cancer 2019;29:981-982.

Received 18 February 2019

Accepted 21 February 2019

Published Online First 3 April 2019

Int J Gynecol Cancer 2019;29:981-982.

\section{REFERENCES}

1. The World Bank, 2014. Available: http//: worldbank.org [Accessed 24 Jan 2019].

2. World Heath Organization. Available: http:// www.who.int/cancer/country-profiles/moz en.pdf [Accessed 24 Jan 2019].

3. Brandão M, Tulsidás S, Damasceno A, et al. Cervical cancer screening uptake in women aged between 15 and 64 years in Mozambique. Eur J Cancer Prev 2018. doi:10.1097/CEJ.0000000000000459. [Epub ahead of print: 16 Jul 2018].

4. Lopez MS, Baker ES, Milbourne AM, et al. Project echo: a Telementoring program for cervical cancer prevention and treatment in low-resource settings. $J$ Glob Oncol 2017;3:658-65. 